\title{
La codicia en el poema "A un Médico Tuerto" de Juan del Valle y Caviedes
}

\author{
Greed in the poem "A un Médico Tuerto" by Juan del Valle y Caviedes \\ A ganância no poema "A un Médico Tuerto" de Juan del Valle y Caviedes \\ Wilber Condori ${ }^{1}$ \\ Universidad Nacional del Altiplano, Perú \\ Estefany Quispe \\ Universidad Nacional del Altiplano, Perú \\ Luz Cuba \\ Universidad Nacional del Altiplano, Perú
}

DOI: https://doi.org/ 10.35622/j.rg.2021.03.002

Recibido 02/06/2021/ Aceptado 15/07/2021

\begin{abstract}
RESUMEN. Este trabajo tuvo como objetivo determinar la concepción de la codicia en el poema "A un médico tuerto" de Juan del Valle y Caviedes desde la perspectiva del análisis del discurso poético. Esta investigación pertenece al enfoque cualitativo y es de tipo descriptivo. El método que se empleó para analizar fue la hermenéutica y como técnica el análisis del discurso poético, que abarcó la dimensión textual, enunciativa, semiótica y pragmática. Como resultado se infiere que la acción de aprovechamiento de la vulnerabilidad de las personas para beneficio personal.
\end{abstract}

PALABRAS CLAVE: Análisis, discurso, semiótica, pragmática, enunciación.

\begin{abstract}
This work aims to determine the concept of code in the poem "A un Médico Tuerto" by Juan del Valle and Caviedes from the perspective of the analysis of poetic discourse. This investigation belongs to the qualitative and descriptive approach. The method used to analyze hermeneutics and, as a technique, poetic speech analysis encompassed the textual, enunciative, semiotic, and pragmatic dimensions. As a result, it is inferred that the action of benefiting the vulnerability of the people for personal benefit.
\end{abstract}

KEYWORDS: Analysis, discourse, semiotics, pragmatics, enunciation.

RESUMO. O objetivo deste trabalho foi determinar a concepção de ganância no poema "A um médico caolho" de Juan del Valle y Caviedes na perspectiva da análise do discurso poético. Esta pesquisa pertence à abordagem qualitativa e é descritiva. O método de análise utilizado foi a hermenêutica e como técnica a análise do discurso poético, que

${ }^{1}$ Correspondencia: ilujanom@est.unap.edu.pe 
abarcou as dimensões textual, enunciativa, semiótica e pragmática. Como resultado, infere-se que a ação de aproveitar a vulnerabilidade das pessoas para benefício pessoal.

PALAVRAS CHAVE: Análise, discurso, semiótica, pragmática, enunciação.

\section{INTRODUCCIÓN}

El poema A un médico tuerto es uno de los poemas más conocidos de Juan del Valle y Caviedes (1645 - 1697). Este autor es conocido como "El poeta de la Rivera" se caracterizó por la cuestión satírica y burlesca en sus escritos. Cortés (1986), afirma que la sátira oscila entre la denuncia moral y el ataque personal. Por otro lado. Hodgart (1969) sostiene que comienza con una postura mental de crítica y hostilidad. Mientras tanto, Freud (1905), en el apartado de su estudio que dedica a las tendencias del chiste identifica la sátira con la dialéctica del ataque y la defensa.Griffin (1994) señala que la sátira es por encima de toda ficción, y no plantea otra cosa que la lucha del bien contra el mal.

Las obras de Juan del Valle y Caviedes han sido estudiadas desde diferentes perspectivas. Sin embargo, nunca se hizo un estudio desde la perspectiva del análisis del discurso. En ese contexto esta investigación se planteó con el objetivo de determinar la concepción de la codicia en la poesía de Juan del Valle y Caviedes.

Séneca, (1986) citado por Valverde (2008), en la $2^{\text {a }}$ Carta a Lucilio, señalaba que en la codicia se ansía lo que falta, lo que queda por adquirir: «No es pobre el que tiene poco, sino el que ambiciona más. Pues, ¿qué importa cuánto caudal encierre en su arca, ¿cuánto en sus graneros, cuánto ganado apaciente o cuántos préstamos haga, si codicia lo ajeno, si calcula no lo adquirido, sino lo que le queda por adquirir?»

Platón sostiene que la codicia es una enfermedad moral de la ciudad, imponente por ser capaz de corromperlo todo, son características de aquellas personas que piensan de manera egoísta, sin preocuparse de las consecuencias en los demás. Sin embargo, la codicia no es un vicio ni una enfermedad que permita exculpar de algún modo al codicioso, sino, como sustentaba Aristóteles y siglos más tarde Spinoza (2002), en su Tratado teológico político, es el gesto máximo de injusticia de la vida en comunidad porque implica desigualdad y perjuicio hacia los demás sin importar cómo afecten sus acciones a la comunidad. 
Según Aisenson (1994), se trata de una inclinación «exagerada» hacia el lucro, de una sed «inmoderada» de dinero.

Buscando información del análisis al poema citado, fácilmente, no se encuentran evidencias de estudio. En ese sentido, esta investigación reivindica su estudio, desde la perspectiva del análisis del discurso.

\section{MÉTODO}

\section{Método}

El método que se empleó para analizar la obra fue la hermenéutica, en ella se tomó en cuenta el aspecto fenomenológico basada en la eidética y la heurística según (Caparrós, 1992; Husserl, 2013; Merleau-Ponty \& Cabanes, 1975); El estructuralismo (Benveniste, 1966; Searle, 1899); (Eco, 1992); (Lévi-Strauss, 1968; Saussure, 1987), Basada en el sector lingüístico y antropológico y el estudio de los signos(Caparrós, 1992; Saussure, 1987).

\section{Técnica de investigación}

La técnica empleada para el estudio fue el análisis del discurso poético basada en los presupuestos teóricos (Dressler, 1997; Van Dijk, 2001), El modelo de interpretación literaria propuesta por Núñez (2019), la estructura de este modelo de interpretación propuesta por Javier Núñez comprende cuatro dimensiones:

a) Dimensión textual: Consiste en analizar el poema como texto para poder construir nuevos mensajes o actos de habla a través del estudio y uso de deícticos. Este análisis comprende la coherencia; es una unidad de sentido cuya función de conexión de las partes forma un todo, considerada una propiedad semántica de los discursos, basados en la interpretación de cada frase individual relacionada con la interpretación de otras frases; la cohesión, es un rasgo del texto a través del cual se desvela el significado del mismo, existe una relación de dependencia entre dos elementos de un texto que pertenecen a distintas oraciones. (Louwerse, 2004; Van Dijk, 2001; Vilarnovo, 1991). 
b) Dimensión Enunciativa: En esta dimensión se toma en cuenta los enunciados que consiste en separar cada idea. También se toma en cuenta los actos de habla o personas del discurso poético.

Calles (1997), señala que la enunciación es un complejo proceso discursivo el cual incluye: el proceso en sí mismo, el acto de apropiación de la lengua, por un locutor y por un receptor.

Por otro lado Núñez (2019), sostiene que tiene que ver con la teoría de la enunciación, el cual inicia con el estudio de los deícticos. Los cuales indican el tiempo, el espacio en que se realiza la enunciación y los interlocutores.

Calsamiglia, H. y Tuson (1999), considera la inserción de un YO y un TÚ mismos que son protagonistas en la actividad de la enunciación. Así mismo, señala que cuando una persona habla no es un ente abstracto, sino un ente social y que presenta a los demás de una manera determinada.

Según la polifonía de Ducrot (1972), indica que en un discurso no sólo encontramos una sola voz, sino varias. Éstas se conocen con el nombre de polifonía: Sujeto lírico, es el desdoblamiento del autor, es decir, la voz que da el autor al individuo que habla en el texto; Sujeto empírico, es quien produce el discurso, es decir, el autor y el Sujeto del enunciado que son los puntos de vista ajenos al autor que aparecen en el discurso.

c) Dimensión Semiótica: Consiste en generar isotopías a partir del poema. Comprende también el análisis de la esencia, la temática y el sentido del poema.

Según Blanco, D. y Bueno (1989), considera que los semas existen en el interior de los lexemas. Éste es considerado como un modelo que facilita la producción del sentido.

Núñez (2019), afirma que las unidades minimas del sentido son los semas que son rasgos distintivos semánticos de los lexemas, éste se presenta en oposición a otros semas del mismo nivel, el cual señala que permitirá establecer una relación.

La semiología propone un acercamiento a la literatura que dé cuenta de la totalidad del proceso comunicativo (emisión, mensaje, recepción) en sus tres niveles (sintáctico, semántico y pragmático), y considera igualmente la obra literaria como un signo que genera 
procesos semióticos de expresión, significación, comunicación, interacción, interpretación y transducción (Naves, 1992).

A lo largo de la historia nos encontramos con distintos estudios que se pueden considerar precedentes de la semiología, pero, sin duda, se debe a Charles Sanders Peirce y Charles Morris la nueva orientación que en la actualidad sigue la semiología. La semiótica es para Peirce la lógica de los signos y este autor la divide en tres secciones (Naves, 1992):

a. una gramática pura cuyo objeto es la naturaleza de los signos.

b. una lógica, que establecería las condiciones de verdad, y, por tanto, se centraría en el análisis de las relaciones de los signos con su objeto.

c. una retórica pura, cuyo objeto sería el estudio de las condiciones de comunicación.

d) Dimensión pragmática: Consiste en el estudio del texto a nivel antropológico, contextual, biografia del autor, lenguaje, etimología y formación de palabras. Esta dimensión, según afirma que estudia el contexto en cuarto niveles: contexto espacio temporal, situacional, sociocultural y cognitivo y explica los significados no convencionales, mismos que tienen que ver con los actos de habla, la pragmática literaria y que adquieren significado gracias al contexto. Considerada parte de la semiótica que trata del origen, usos y efectos de los signos. El interpretante de un simbolo debe buscarse en un hábito y no en una reacción fisiológica inmediata (Morris, 1985; Núñez, 2019).

Por otra parte Morris (1985), da una definición más específica de la pragmática al precisar que "es la parte de la semiótica que trata del origen, usos y efectos de los signos". Coincide con Peirce al considerar que el interpretante de un simbolo debe buscarse en un hábito y no en una reacción fisiológica inmediata, idea ésta que favoreció el desarrollo de los aspectos pragmáticos.

La semiología propone un acercamiento a la literatura que dé cuenta de la totalidad del proceso comunicativo (emisión, mensaje, recepción) en sus tres niveles (sintáctico, semántico y pragmático), y considera igualmente la obra literaria como un signo que genera procesos semióticos de expresión, significación, comunicación, interacción, interpretación y transducción (Naves, 1992). 
Naves (1992), la siguiente definición de pragmática: "Un concepto más amplio de la pragmática, que se aplica generalmente en la pragmática del texto literario, la presenta como el estudio de las relaciones del texto con su emisor, del texto con su receptor, del texto con su contexto (textual o social), y del texto con los sistemas culturales envolventes".

\section{RESULTADOS Y DISCUSIONES}

\subsection{Cuerpo de estudio}

\section{A un médico tuerto}

(Juan del Valle y Caviedes)

Tuerto dos veces, por vista la una y la otra por ciencia, pues en la endiablada tuya nunca haces cosa a derechas.

No llames siempre ante-ojos a los que traes, porque a medias ante-tuerto has de llamarlos, pues la mitad está a ciegas.

Si no tienes más que un ojo ociosa está una vidriera; parece remedio tuvo por cosa que no aprovecha.

Sin embargo, eres el rey en la medical ceguera; si todos a ciegas curan tú no, que curas a tuertas.

Tu vista nadie la entiende, pues ni se repara en ella tú no miras sino apuntas, tú no ves, sino que asestas.

¿Cómo si apuntando curas 
no atinas con las recetas, pues das tan lejos del mal que todas las curas yerras?

A los enfermos les comes las comidas y aun las cenas para hacerles este mal y que se mueran de dieta.

Ayúdales a beber tus malditas purgas puercas,

y les darás media vida y tú tendrás otra media.

De las ayudas eleves parte también, que les echas,

y ejercitarás dos ojos que en un tuerto es cosa nueva.

Que el comerles las viandas no es curarle las dolencias, sino curarte del hambre canina que te atormenta.

Si con los enfermos curas tus hambres y tus pobrezas, ellos los médicos son tú el enfermo que remedian.

Media visita debían pagarte, en Dios y en conciencia, que quien medio ve al enfermo no debe llevarla entera.

Del Callao te han echado, con descrédito de albéitar, por enjalma de Galeno, por limillo de Avicena.

Hinchate, doctor, de paja, que las albardas rellenas no matan tanto, y tendrás hecho tu plato con ellas. 
Que eres albarda no hay duda,

y me remito a la prueba,

pues la medicina tuya

por ser de albarda está en jerga.

\section{Análisis del poema "A un médico tuerto" en las dimensiones textual, enunciativa, semiótica y pragmática}

\subsection{Dimensión textual}

En el poema "A un médico tuerto" se observa catorce enunciados claramente identificables tal como se presenta en la Tabla 1, los cuales están interrelacionados y en conjunto forman el texto.

Tabla 1 Enunciados del poema A un médico tuerto

\section{Enunciados}

1. Tuerto dos veces, por vista/, / la una y la otra por ciencia/, / pues en la endiablada tuya/, / nunca haces cosas a derechas /

2. / No llames siempre anteojos/, / a los que traes, porque a medias/, /ante tuerto has de llamarlos/, / pues la mitad está a ciegas/

3. /Si no tienes más que un ojo/, / ociosa está una vidriera/, / parece remedio tuvo/, / por cosa que no aprovecha/.

4. /Sin embargo eres el rey/, / en la medical ceguera/, /si todos a ciegas curan/, / tú no, que curas a tuertas /

5. /Tu vista nadie la entiende/, / pues ni se repara en ella/, / tú no miras sino apuntas/, / tú no ves, sino que asestas/, / ¿Cómo si apuntando curas /, / no atinas con las recetas/, / pues das tan lejos del mal/ /que todas las curas yerras? /

6. /A los enfermos les comes/, /las comidas y aun las cenas/, / para hacerles este mal/ /y que se mueran de dieta. /

7. /Ayúdales a beber/, /tus malditas purgas puercas/, /y les darás media vida/, /y tú tendrás otra media/

8. /De las ayudas eleves/, / parte también, que les echas/, /y ejercitarás dos ojos/, / que en un tuerto es cosa nueva. /

9. /Que el comerles las viandas/, / no es curarle las dolencias/, /sino curarte del hambre/, / canina que te atormenta/

10. /Si con los enfermos curas/ / tus hambres y tus pobrezas / / ellos los médicos son/ / tú el enfermo que remedian/

11. /Medias visitas debían pagarte/, / en Dios y en conciencia/, /que quien medio ve al enfermo/ / no debe llevarla entera/

12. /Del Callao te han echado/, /con descrédito de albéitar/, / por enjalma de Galeno/, / por limillo de Avicena/. 
13. /Hínchate, doctor, de paja/, /que las albardas rellenas/ /no matan tanto, y tendrás/ / hecho tu plato con ellas/

14. /Que eres albarda no hay duda/, /me remito a la prueba/, / pues la medicina tuya/ / por ser de albarda está en jerga/.

En el primer enunciado el mecanismo de cohesión es la conjunción "pues" que cumple la función de relacionar el agente tuerto dos veces, por vista y la otra por ciencia con el verso en la endiablada tuya nunca haces cosas a derechas.

En el segundo enunciado se observan dos mecanismos de cohesión, el primero es la conjunción "porque" (causal) que explica al primer verso no llames siempre ante-ojos a los que traes" el segundo conector es la conjunción "pues" que une el verso a medias ante-tuerto has de llamarlos con el verso la mitad está a ciegas.

El tercer enunciado presenta la conjugación del verbo "parece" que une al verso Si no tienes más que un ojo ocioso está una vidriera con el verso remedio tuvo por cosa que no aprovecha.

En el cuarto enunciado el mecanismo de cohesión es la conjunción "si" luego encontramos a la conjunción "que" los mismos relacionan todo el enunciado.

En el quinto enunciado se observan dos mecanismos de cohesión, el primero viene a ser la conjunción "pues" que une el verso remedio tuvo por cosa que no aprovecha con el verso ni se repara en ella tú no miras sino apuntas; el siguiente mecanismo de cohesión es la conjunción "que" el cual cumple la función de relacionar el segundo verso con el tercer verso.

El sexto enunciado posee la conjunción "y" que cumple la función de enlazar el verso para hacerles este mal con el verso que se mueran de dieta.

En cuanto al séptimo enunciado se repite la conjunción "y" que relacionan los versos de este enunciado.

En el octavo enunciado el primer conector es la conjunción "y" mientras que el segundo es la conjunción "que" los cuales enlazan el enunciado. 
El noveno enunciado posee la conjunción adversativa "sino" que relaciona el verso no es curarle las dolencias con el verso curarte del hambre.

El décimo enunciado presenta el pronombre "ellos" que cumple la función de relacionar el verso tus hambres y tus pobrezas con el verso ellos los médicos son.

El décimo primer enunciado evidencia la conjunción "que" el cual une el verso en Dios y en conciencia con el verso quieren medio ve al enfermo.

En el décimo segundo, el mecanismo de cohesión es la preposición "por" el cual une al verso por enjalma de Galeno con el verso por limillo de Avicena formando una anáfora.

El décimo tercer enunciado exhibe dos mecanismos de cohesion; el primero es la conjunción "que" mientras que el segundo es la conjunción " $y$ " los cuales relacionan el enunciado. El último enunciado presenta el conector "pues" el cual une al verso me remito a la prueba con el verso pues la medicina tuya del enunciado.

Tabla 2 Tema y título del poema A un médico tuerto.

\section{Tema}

La codicia de un médico.
Título

A un médico tuerto.

Tabla 3 Idea principal y resumen del poema A un médico tuerto

\section{Idea principal}

La codicia de un médico tuerto con poco conocimiento en la medicina.

\section{Resumen}

Médico codicioso que se aprovecha de la vulnerabilidad de las personas enfermas y de escasos recurso para beneficiarse económicamente. 


\subsection{Dimensión enunciativa}

\section{Actos de habla}

El deíctico "tuya" permite establecer la voz que habla. Esta voz corresponde a la segunda persona.

¿Quién habla y a quién se dirige?

El sujeto que habla en el poema "A un médico tuerto" es el sujeto lírico, un Yo creado por el autor, que se dirige a un médico.

\section{Sujetos del discurso:}

\section{- Sujeto lírico:}

El poema "A un médico tuerto" de Juan del Valle y Caviedes, el sujeto lírico es el YO creado por el autor.

\section{- Sujeto empirico o juridico:}

Juan del Valle y Caviedes.

\subsection{Dimensión semiótica}

En el poema "A un médico tuerto" se analizarán los siguientes lexemas:

Tabla 4

\begin{tabular}{cl}
$\begin{array}{c}\text { Lexemas } \\
\text { (primer enunciado) }\end{array}$ & \multicolumn{1}{c}{ Semas que genera } \\
\hline Tuerto & Ciego, carencia de un ojo. \\
Vista & $\begin{array}{l}\text { Mirada, visualización, observación, visión, } \\
\text { panorama. }\end{array}$ \\
Ciencia & Conocimiento, sabiduria, erudición, tecnología. \\
Endiablada & $\begin{array}{l}\text { Perverso, maldito, endemoniado, malvado, } \\
\text { colérico, poseído. }\end{array}$ \\
Nunca & Jamás, negación. \\
Derechas & Correcto, justo, recto, legal, razonable. \\
\hline
\end{tabular}


Podemos manifestar que en el primer enunciado del poema que comienza del verso 1 hasta el verso 4. De este tópico los lexemas a analizar son "tuerto" "vista" "ciencia", "endiablada", "nunca", "derechas"

Los semas más comunes fueron:/ciego/ /visión/conocimiento/ /perverso/ /jamás/justo/

De los semas comunes podemos deducir que el poeta le dice al médico que no tiene una buena visión de conocimiento ante su trabajo, lo cual es perverso y jamás hace lo justo con sus pacientes.

La oposición de semas es de la siguiente forma:

/ ciego/ vs / vidente/

/visión/ vs /ceguera/

/conocimiento/ vs /ignorancia/

/ perverso/ vs / bondadoso

\begin{tabular}{cl}
\hline $\begin{array}{c}\text { Lexemas } \\
\text { (segundo enunciado) }\end{array}$ & \multicolumn{1}{c}{ Semas que genera } \\
\hline anteojos & Gafas, lentes, ceguedad. \\
a medias & La mitad, incompleto, vacío. \\
llames & Invocar, vociferar, convocar, nombrar, mencionar. \\
traes & $\begin{array}{l}\text { Transportar, trasladar, guiar, conducir, llevar, } \\
\text { adquirir. } \\
\text { mitad }\end{array}$ \\
\hline
\end{tabular}

Podemos manifestar que la segunda idea del poema, comienza del verso 5 hasta el verso 8 , de este tópico de lexemas a analizar son: "anteojos", "a medias", "llames", "traes", "mitad"

Los semas más comunes fueron: /ceguedad/ la $\mathrm{mitad} / \mathrm{mencionar} /$ guiar/

De los semas comunes podemos expresar que el médico es ciego de un ojo, lo cual no puede sanar a sus pacientes por completo. 
Lexemas

(tercer

enunciado)

Semas que genera

tienes Tener, obtener, propiedad, beneficiario.

ojo Vista, visión, mirada.

ociosa Floja, vaga, desocupado, inactivo, perezoso, holgazán, haragán.

vidriera Ventanal

remedio Cura, antídoto, remedio, reparación, medicina, arreglo, alivio.

cosa Objeto, cuerpo, materia.

no-aprovechar Desaprovechar, desperdiciar, malgastar, derrochar.

En el tercer enunciado, que inicia desde el verso 9 hasta el verso 12, cuyos lexemas a analizar son: "tienes", "ojo", "ociosa", "vidriera", "remedio", "cosa", "no-aprovechar".

Los semas más comunes fueron:/tener/, /visión/, /haragán/, /medicina/, /objeto/, /desaprovechar/.

De los semas comunes podemos deducir: el autor le dice al médico que tiene una visión de un haragán, que las medicinas que tiene las desaprovecha.

\begin{tabular}{cl}
\hline $\begin{array}{c}\text { Lexemas } \\
\text { (cuarto } \\
\text { enunciado) }\end{array}$ & \multicolumn{1}{c}{ Semas que genera } \\
\hline rey & $\begin{array}{l}\text { Señor, jefe, lider, majestad, gobernador, emperador, } \\
\text { soberano, monarca. }\end{array}$ \\
ceguera & $\begin{array}{l}\text { Corto de vista, invidente, miopía, dolor, tristeza, } \\
\text { amargura. }\end{array}$ \\
ciegas & $\begin{array}{l}\text { que no ven. } \\
\text { curan }\end{array}$ \\
Curar, antidoto, remediar, reparación, medicina, \\
arreglo, alivio. \\
Cura, antidoto, remedio, reparación, medicina, \\
tuertas
\end{tabular}$\quad$\begin{tabular}{l} 
Ciego, carencia de un ojo. \\
\hline
\end{tabular}


En el cuarto enunciado, que inicia desde el verso 13 hasta el verso 16, cuyos lexemas a analizar son: "rey", "ceguera", "ciegas", "curan", "curas"

Los semas más comunes fueron: /ceguera/visión/remediar/amargura/curar/

De los semas comunes podemos deducir que el poeta afirma que el médico es el rey de la ceguera que, aunque tenga conocimiento completo, no cura completamente sino a medias.

\begin{tabular}{|c|c|}
\hline $\begin{array}{l}\text { Lexemas } \\
\text { (quinto } \\
\text { enunciado) }\end{array}$ & Semas que genera \\
\hline Vista & $\begin{array}{l}\text { Mirada, visualización, observación, visión, } \\
\text { panorama. }\end{array}$ \\
\hline nadie entiende & incomprensión, desacuerdo, confusión. \\
\hline no se repara & irreparable, irremediable, incurable, perdido. \\
\hline no miras & engaño, falsedad, farsa, fraude, estafa, embuste. \\
\hline Apuntar & juzgar, criticar, direccionar. \\
\hline no ves & no ve, no observa, no distingue. \\
\hline Acestas & pegar, golpear, dar un golpe, dirigir. \\
\hline apuntando curas & $\begin{array}{l}\text { juzgando curas, criticando curas, adivinando } \\
\text { sanas. }\end{array}$ \\
\hline no atinas & $\begin{array}{l}\text { no aciertas, no descubre, no encuentra, errar, } \\
\text { fallar, equivocarse. }\end{array}$ \\
\hline Recetas & fórmula, composición, prescripción. \\
\hline lejos & alejado, lejano. \\
\hline Mal & daño, perjuicio. \\
\hline Yerras & equivocación, fallar, engaño. \\
\hline
\end{tabular}

En el quinto enunciado, que inicia desde el verso 17 hasta el verso 24, cuyos lexemas a analizar son: "vista", "nadie entiende", "no se repara", "no miras", "apuntar", "no ves", "acestas", "apuntando curas", "no atinas", "recetas", "lejos", "mal”, "yerras". 


\begin{tabular}{cl}
\hline $\begin{array}{c}\text { Lexemas } \\
\text { (sexto } \\
\text { enunciado) }\end{array}$ & \multicolumn{1}{c}{ Semas que genera } \\
\hline enfermos & dañado, infectado, indispuesto. \\
comes & alimentarse, almorzar. \\
comidas & alimento, sustento, almuerzo, banquete. \\
cenas & comida, alimento, sustento. \\
hacerles el mal & dañarles, lastimar, perjudicar. \\
mueran & fenecer, morir, sucumbir, agonizar, finar. \\
dieta & ayuno, tratamiento, régimen, abstinencia. \\
\hline
\end{tabular}

En el sexto enunciado, que empieza con el verso 25 hasta el verso 28 , cuyos lexemas a analizar fueron: "enfermos", "comes", "comidas", "hacerles el mal", "mueran", "mueran", "dieta".

los semas más comunes fueron /alimento/, /sustento/, /lastimar/ de los semas más comunes podemos deducir: que el autor, a través del sujeto lírico, le dice al médico que a los a los enfermos les arrebata el alimento haciendo que se mueran de hambre.

\begin{tabular}{cl}
\hline $\begin{array}{c}\text { Lexemas } \\
\text { (séptimo } \\
\text { enunciado) }\end{array}$ & \multicolumn{1}{c}{ Semas que genera } \\
\hline ayudales & auxilio, asistencia, amparo, socorro. \\
beber & ingerir, tomar, ingerir. \\
purgas & laxante, medicina, depurador. \\
puercas & sucio, astroso. \\
media vida & cuasi existencia, supervivencia, corta duración. \\
media & mitad, incompleto, faltante. \\
\hline
\end{tabular}

En el séptimo enunciado, que empieza con el verso 29 hasta el verso 32, cuyos lexemas a analizar son: "ayudales", "beber", "purgas", "puercas", "media vida" y "media" 


\section{Lexemas \\ (octavo \\ Semas que genera \\ enunciado)}

$$
\begin{array}{cl}
\text { ayudas } & \text { apoyar, impulsar, socorrer, colaborar. } \\
\text { eleves } & \text { levantar, subir, alzar, ascender, crecer. } \\
\text { echas } & \text { expulsar, exiliar, lanzar, repeler. } \\
\text { ejercitarás } & \text { entrenar, practicar. } \\
\text { ojos } & \text { vista, sentido, lucero. } \\
\text { tuerto } & \text { torcido, daño, ciego, carencia de un ojo. } \\
\text { cosa nueva } & \text { novedoso, primicia, invento. }
\end{array}
$$

En el octavo enunciado que empieza con el verso 33 hasta el verso 36, cuyos lexemas a analizar son "ayudas", "eleves", "echas", "ejercitaras", "ojos", "tuerto", "cosa nueva"

Los semas más comunes fueron: /socorrer/, /practicar/, /vista/, /torcido/.

De los semas más comunes podemos deducir que: el autor, a través del sujeto lírico, menciona que de las ayudas que el médico haga a los demás, verá que ayudar es algo nuevo para él.

\begin{tabular}{cl}
\hline $\begin{array}{c}\text { Lexemas } \\
\text { (noveno } \\
\text { enunciado) }\end{array}$ & \multicolumn{1}{c}{ Semas que genera } \\
\hline Comer & $\begin{array}{l}\text { alimentarse, nutrirse, consumir, disipar, } \\
\text { saciarse. }\end{array}$ \\
Viandas & manjar, alimento, comida, sustento, plato \\
Curar & sanar, tratar, medicar, cuidar, mejorar aliviar \\
Dolencia & $\begin{array}{l}\text { sufrimiento, padecimiento, dolor, daño, trastorno, } \\
\text { mal } \\
\text { Hambre }\end{array}$ \\
$\begin{array}{l}\text { apetencia, glotoneria, necesidad, hambriento, } \\
\text { polifagia, saciedad } \\
\text { torturar, angustiar, martirizar, agobiar, abrumar, } \\
\text { preocupar, amarfar, afligir }\end{array}$ \\
\hline
\end{tabular}


En el noveno enunciado, que empieza con el verso número $37 \mathrm{y}$ termina en el verso número 40, cuyos lexemas a analizar son: "comer", "viandas", "curar", "dolencia", "hambre", "atormenta".

Los semas más comunes fueron: /consumir/, /alimento/, /medicar/, /sufrimiento/, /apetencia/, /abrumar/. de los semas más comunes podemos deducir que el autor, a través del sujeto lírico manifiesta que: el quitar el alimento no es sanar los males, es causar un sufrimiento abrumador que atormenta a los demás.

\begin{tabular}{|c|c|}
\hline $\begin{array}{l}\text { Lexemas } \\
\text { (décimo } \\
\text { enunciado) }\end{array}$ & Semas que genera \\
\hline Enfermos & paciente, infectado, indispuesto. \\
\hline Curas & $\begin{array}{l}\text { sanar, remediar, tratar, medicinar, cuidar, } \\
\text { mejorar, aliviar. }\end{array}$ \\
\hline Hambres & $\begin{array}{l}\text { apetencia, glotoneria, necesidad, hambriento, } \\
\text { polifagia, hambre. }\end{array}$ \\
\hline Pobrezas & miseria, carencia, escase $z$, falta, necesidad \\
\hline Medico & doctor, terapeuta, cirujano, galeno \\
\hline Remedian & $\begin{array}{l}\text { sanar, tratar, medicinar, recetar, vendar, } \\
\text { desinfectar, atender, cuidar. }\end{array}$ \\
\hline
\end{tabular}

En el décimo enunciado que empieza con el verso 41 y termina con el verso 44, cuyos lexemas a analizar son: "enfermos", "curar", "hambres", "pobrezas", "médico", "remedian".

Los semas más comunes fueron:/paciente/, /sanar/, /hambre/, /miseria/, /doctor/, /curar/.

De estos semas podemos deducir que: el autor, a través de lo sujeto lírico afirma al médico, que, si robando a los enfermos remedia su glotonería, entonces el enfermo es el, mas no sus pacientes, puesto que, los pacientes remedian sus necesidades.

\begin{tabular}{cl}
\hline $\begin{array}{c}\text { Lexemas } \\
\text { (onceavo } \\
\text { enunciado) }\end{array}$ & \multicolumn{1}{c}{ Semas que genera } \\
\hline Medio & mitad, fracción, cortado. \\
Visita & visitante, invitado, convidado, cita, entrevista. \\
\hline
\end{tabular}


Pagarte

Dios

Conciencia

Medio

Enfermo

Entero remunerar, retribuir, gratificar, compensar.

divinidad, espiritual, divinidad, creador, todopoderoso.

conocimiento, entendimiento, moralidad, pensamiento.

mitad, regular, fracción,

paciente, indispuesto, infectado, aquejado, contagiado, infeccioso, doliente.

completo, lleno, entero, acabado,

En el onceavo enunciado que empieza con el verso 45 y termina con el verso 48, cuyos lexemas a analizar son: "media", "vista", "pagarte", "dios", "conciencia", "medio", "enfermo", "entero".

Los semas más comunes fueron:/mitad/, /remunerar/, /creador/, /conocimiento/, /mitad/, /paciente/, /completo/.

De los semas más comunes podemos deducir que el autor dice al doctor que solo deberían darle la mitad de la remuneración, porque la otra mitad debe dárselo el creador puesto que, lo tiene en su conciencia.

\begin{tabular}{cl}
\hline $\begin{array}{c}\text { Lexemas } \\
\text { (doceavo } \\
\text { enunciado) }\end{array}$ & \multicolumn{1}{c}{ Semas que genera } \\
\hline echado & $\begin{array}{l}\text { confinado, desterrado, expulsado, deportado, } \\
\text { repudiado }\end{array}$ \\
Descredito & $\begin{array}{l}\text { desprestigio, deshonor, denigración, } \\
\text { descalificación, desmerecimiento }\end{array}$ \\
Albéitar & $\begin{array}{l}\text { Veterinario } \\
\text { almohadilla, silla, soporte } \\
\text { Enjalma }\end{array}$ \\
Galeno & doctor, médico, facultativo, sanador. \\
\hline
\end{tabular}

El doceavo enunciado que empieza con el verso 49 y culmina con el verso 52, cuyos lexemas a analizar son: "echado", "descrédito", "albéitar", "enjalma", "galeno".

Los semas más comunes son: /desterrado/, /deshonor/, /doctor/. 
De los semas más comunes se puede deducir que le han desterrado con deshonor por no tener principios de un doctor.

\begin{tabular}{cl}
\hline $\begin{array}{c}\text { Lexemas } \\
\text { (treceavo } \\
\text { enunciado) }\end{array}$ & \multicolumn{1}{c}{ Semas que genera } \\
\hline Hinchate & aumentar, agrandar, \\
Doctor & médico, terapeuta, cirujano, galeno \\
Paja & forraje, hierba, broza, hojarasca \\
albardas & $\begin{array}{l}\text { apajero, montura, albardera, almohadilla, silla, } \\
\text { guarnicioneria. } \\
\text { Repleto, abarrotado, henchido, saturado, } \\
\text { atestado, atiborrado, colmado. } \\
\text { Asesinar, ajusticiar, ejecutar, inmolar, } \\
\text { Matan }\end{array}$ \\
Plato & \begin{tabular}{l} 
bandeja, escudilla, fuente, \\
\hline
\end{tabular}
\end{tabular}

En el enunciado trece, que empieza con el verso 53 y termina con el verso 56, cuyos lexemas a analizar son: "hínchate", "doctor", "paja”, "albardas", "relleno", "matan", "plato".

Los semas más comunes son: /aumentar/, /médico/, /forraje/, /asesinar/.

De los semas más comunes se deduce que el autor se burla del médico diciendo que no podrá sacar más provecho de los pobres.

\begin{tabular}{cl}
\hline $\begin{array}{c}\text { Lexemas } \\
\text { (catorceavo } \\
\text { enunciado) }\end{array}$ & \multicolumn{1}{c}{ Semas que genera } \\
\hline Albarda & montura, silla, \\
no hay duda & sin titubeo, que es seguro, \\
remitir a la prueba & $\begin{array}{l}\text { atenerse a la comprobación, verificación, } \\
\text { demostración }\end{array}$ \\
Medicina & cura, remedio, antidoto, \\
jerga & argot, germanía, jerigonza. \\
\hline
\end{tabular}


En el enunciado catorce que empieza con el enunciado 57 y termina en el enunciado 60, cuyos lexemas a analizar son: "albarda", "no hay duda", "remitir a la prueba", "medicina”, "jerga".

Los semas más comunes son: /seguridad/, /demostrar/, / remedio/. De los semas más comunes se deduce que el autor afirma que no cabe duda que la medicina del doctor no es buena y tiene pruebas, por ello se burla del doctor.

\section{4. Dimensión pragmática}

Niveles de discurso

Nivel locutivo: En el poema se han encontrado quince enunciados, los cuales a nivel locutivo explican que: el hablante lírico critica la acción de un "tú" (el médico) de esta manera el sujeto lírico delata la situación del médico(tú) afirmando y criticando la situación real del médico.

Nivel ilocutivo: Se entiende que el sujeto lírico expresa remordimiento, cólera e indignación hacia el médico, además, nos da a conocer sobre un médico codicioso que roba a la sociedad pobre.

Nivel perlocutivo: A nivel perlocutivo el poema causa cólera desde una manera satírico-burlesco. El autor entra en el poema para mostrarnos el mundo degradado que ocasiona la codicia en su época. $Y$ se inserta dentro de ella para ofrecernos por contraste un mundo degradado.

\section{CONCLUSIONES}

El poema de Juan del Valle y Caviedes es claramente una manifestación de burla y crítica a los atropellos de su entorno, juzgando a una persona que obra de manera codiciosa; a partir de ello, se puede deducir que el significado de codicia que se ha encontrado dentro del poema a un médico tuerto es la acción de aprovecharse de la vulnerabilidad de la gente con fines económicos y personales.

En cuanto a la manifestación del autor, se puede concretar que vivió en carne propia el contraste de su época y sufrió las consecuencias procedentes de un mundo degradado en la codicia y la desigualdad, 
al margen de inclinarse a producir versos satíricos en función a temas de su entorno en que vivia y juzgaba.

Se puede afirmar que las ideas provenientes en su poema no son meras inspiraciones, ya que demuestran fuertes expresiones de dolor, angustia, cólera y reclamos hacia una persona que está implícito en el poema.

La obra del autor está vinculada a dejar en descubierto la figura de una sociedad injusta, que abusa de la condición del humilde al límite de robarles hasta el último recurso de subsistencia y dejarle en la agonía de la pobreza.

\section{REFERENCIAS}

Aisenson, A. (1994). Resolución de conflictos: un enfoque psicosociológico. Sección De Obras De Psicología, Psiquiatría y Psicoanálisis.

Benveniste, E. (1966). Problèmes de linguistique générale.

Schoenhof's Foreign Books, Incorporated, 1.

Blanco, D. \& Bueno, R. (1989). Metodología de análisis semiótico.

Calles, M. J. (1997). Modalización del discurso poético.

Calsamiglia, H. \& Tuson, A. (1999). Las cosas del decir: Manual del análisis del discurso (Ariel, Ed.). Barcelona.

Caparrós, J. D. (1992). Ch. S. Peirce y la teoría literaria. Signa, 1, 169-178.

Cortés Tovar, R. (1986). Teoría de la sátira: análisis de

Apocolocyntosis de Séneca. Universidad de Extremadura.

Dressler, W. U. (1997). Introducción a la lingüistica del texto (Ariel). Madrid.

Ducrot, O. (1972). Decir y no decir: principios de semántica lingüistica (Anagrama). Barcelona.

Eco, U. (1992). Los limites de la interpretación (Lumen). Barcelona.

Freud, S. (1905). El chiste y su relación con lo inconsciente (Alianza). Madrid.

Griffin, D. H. (1994). Satire: A critical reintroduction. University Press of Kentucky.

Hodgart, M. (1969). La sátira, trad. de Angel Guillén. Madrid, Guadarrama, 24.

Husserl, E. (2013). Ideas relativas a una fenomenología pura y una filosofia fenomenológica. Libro primero: Introducción general a 
la fenomenología pura. México: FCE.

Lévi-Strauss, C. (1968). Estructuralismo y dialéctica. Editorial Paidos.

Louwerse, M. M. (2004). Un modelo conciso de cohesión en el texto y coherencia en la comprensión. Revista Signos, 37(56), 41-58.

Merleau-Ponty, M., \& Cabanes, J. (1975). Fenomenología de la percepción. Península Barcelona.

Morris, C. (1985). Fundamentos de la teoría de los signos (Paidós). Barcelona.

Naves, B. (1992). Spanisch: Pragmalinguistik (Síntesis). Madrid.

Núñez, J. (2019). El poema XI de Alberto Mostajo a la luz del Análisis del Discurso. Revista Innova Educación.

https://doi.org/10.35622/j.rie.2019.02.008

Saussure, F. (1987). Curso de lingüística general (Alianza). Madrid.

Searle, J. (1899). Chomsky y la revolución lingüística. Bolitín de Matemáticas.

Spinoza, B. (2002). Tratado teológico político (1670). Barcelona: Folio.

Valverde, A. (2008). La estructura compositiva de las" Epístolas morales a Lucilio" de Séneca. Habis, 39, 143-151.

Van Dijk, T. (2001). Esructuras y funciones del discurso: una introducción interdisciplinaria a la lingüística del texto y a los estudios del discurso (Siglo XXI). Argentina.

Vilarnovo, A. (1991). Teorias explicativas de la coherencia textual. Revista Española de Lingüística. 